\begin{tabular}{|c|c|}
\hline Title & Parameter sensitivity studies for the ice flow of the Ross I ce Shelf, A ntarctica \\
\hline Author(s) & Humbert, A ngelika; Greve, Ralf; Hutter, Kolumban \\
\hline Citation & $\begin{array}{l}\text { Journal of Geophysical Research, 110(f4), F04022 } \\
\text { https://doi.org/10.1029/2004JF000170 }\end{array}$ \\
\hline Issue Date & $2005-12-10$ \\
\hline Doc URL & http:/hdl.handle.net/2115/29714 \\
\hline Rights & $\begin{array}{l}\text { A n edited version of this paper was published by A GU. Copyright } 2005 \text { A merican Geophysical Union. } \\
\text { Humbert, A ngelika, Greve, Ralf, Hutter, Kolumban, (2005), Parameter sensitivity studies for the ice flow of the Ross } \\
\text { Ice Shelf, A ntarctica, Journal of Geophysical Research, 110, F04022, 10.1029/2004JF000170. To view the published } \\
\text { open abstract, go to http://dx.doi.org/10.1029/2004JF000170. }\end{array}$ \\
\hline Type & article (author version) \\
\hline File Information & JGR110-F4.pdf \\
\hline
\end{tabular}

Instructions for use 
J. Geophys. Res. 110 (F4), F04022, 2005

http://www.agu.org/pubs/

- Authors' final version -

\title{
Parameter sensitivity studies for the ice flow of the Ross Ice Shelf, Antarctica
}

\author{
Angelika Humbert (1), Ralf Greve (2)* \\ and Kolumban Hutter (1)
}

(1) Institute of Mechanics III, Darmstadt University of Technology, Hochschulstraße 1, D-64289 Darmstadt, Germany

(2) Institute of Low Temperature Science, Hokkaido University, Kita-19, Nishi-8, Kita-ku, Sapporo 060-0819, Japan

* Formerly at Institute of Mechanics III, Darmstadt University of Technology, Darmstadt, Germany

December 15, 2005

Correspondence to: A. Humbert (humbert@mechanik.tu-darmstadt.de) 


\begin{abstract}
The diagnostic, dynamic/thermodynamic ice-shelf model FESSACODE (Finite Element Shallow-Shelf-Approximation Code) is applied to the Ross Ice Shelf. We simulate the present ice flow which results from the ice-thickness distribution, the inflow at the grounding line and the surface and bottom temperature, and compare results with measured flow velocities. Our reference simulation reproduces the general flow pattern and the magnitudes of the flow velocities reasonably well. The ice flow is found to be very sensitive to the flow enhancement factor, the ice thickness and the ice temperature, but robust against inflow velocities from ice streams, glaciers and ice rises. The ice rises (Roosevelt Island, Crary Ice Rise) stabilize the ice shelf by significantly decreasing the flow velocities for the entire ice-shelf area. The ice shelf is susceptible to global warming, in that a $2^{\circ} \mathrm{C}$ surface warming entails an increase of the flow velocities by a factor 1.25 , whereas a $10^{\circ} \mathrm{C}$ warming leads to an increase by a factor 3.1 .
\end{abstract}

\title{
1 Introduction
}

The Antarctic ice shelves are of great importance for the dynamics of the entire Antarctic ice sheet because they drain approximately $90 \%$ of the coastward mass flux of the inland ice via a relatively small number of fast moving ice streams and outlet glaciers (Bamber and Vaughan 2000). The Ross Ice Shelf is the largest of the Antarctic ice shelves with an area of approx. $490000 \mathrm{~km}^{2}$, situated in a huge embayment of the Antarctic continent (Figure 1). The ice shelf is afloat everywhere except for two large ice rises, Roosevelt Island and Crary Ice Rise, and some smaller features like the Stearshead Crevasses and the ice plain downstream of the grounding line of Whillans Ice Stream. The ice rises form small grounded ice caps that are dynamically separated from the ice shelf. Inflow from the inland ice occurs mainly by the five major ice streams from the West-Antarctic Shirase, Siple and Gould Coast (for simplicity, we will refer to it as "Siple Coast" in the following) and a number of glaciers from East Antarctica which enter through the steep coast of the Transantarctic Mountains. Therefore, inflow from the West Antarctic Ice Sheet is far greater than from the East Antarctic Ice Sheet, and the Ross Ice Shelf may play a crucial role for the stability of the former.

The Ross Ice Shelf is well suited for a dynamic/thermodynamic modelling study because of the good data coverage. Ice velocities were measured in the Ross Ice Shelf Geophysical and Glaciological Survey (RIGGS) campaign (Thomas et al. 1984) and determined from satellite imagery by Bindschadler and Scambos (1991), Scambos et al. (1992), Bindschadler et al. $(1996,1997)$ (data archived by the National Snow and Ice 


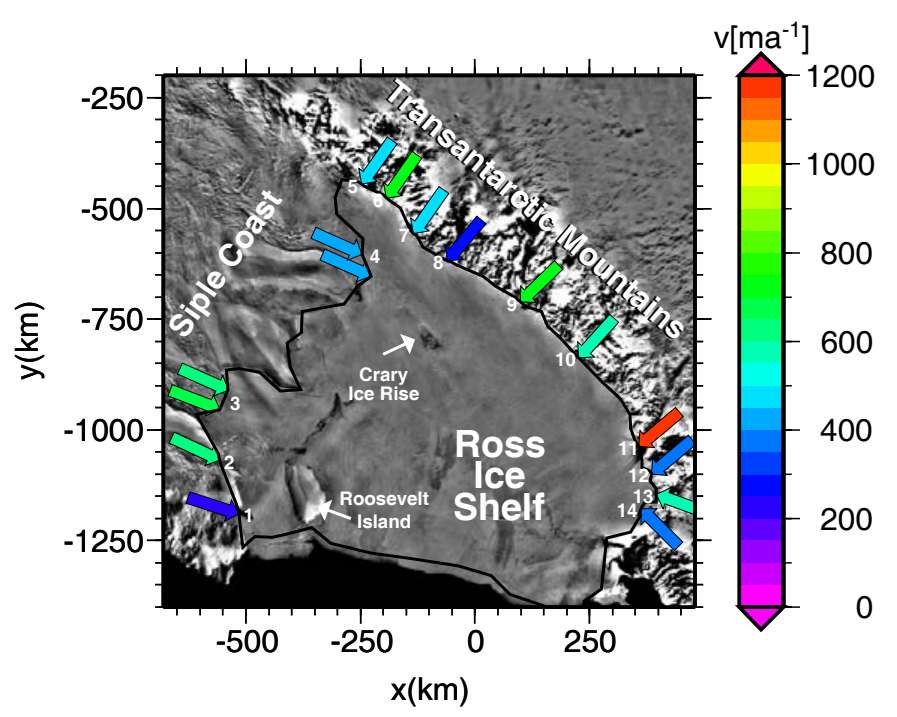

Figure 1: Overview of the Ross Ice Shelf. The solid black line indicates the newlydetermined grounding line. Arrows mark inflowing ice streams and glaciers, their numbering corresponds to that of Table 2, and the colour code denotes inflow velocities. Credit of background AVHRR image: TerraWeb, U. S. Geological Survey, Flagstaff, Arizona, http://terraweb.wr.usgs.gov/.

Data Center, NSIDC). The ice-thickness distribution can be inferred from the BEDMAP data-set (Lythe et al. 2000). Already in the 1990's, the ice shelf was used as a test case for an intercomparison of the different dynamic ice-shelf models available at that time (MacAyeal et al. 1996). Of these models, the 'Grenoble' (Rommelaere and Ritz 1996), 'Chicago1' (MacAyeal and Thomas 1986) and 'Bremerhaven1' models (Huybrechts 1990) were based on the same system of dynamic equations which will be applied here [Sect. 2, Eqs. (2)], whereas the 'Bremerhaven2' model (Determann 1991) used a simplified version in which horizontal gradients of the effective viscosity [Eq. (3)] are not accounted for, so that velocity gradients are uncoupled from ice-thickness gradients. As for the numerical solution technique, the 'Bremerhaven1/2' and 'Grenoble' models employed finitedifference (FD) techniques, and the 'Chicago1' model was based on a finite-element (FE) scheme. It was shown that the 'Grenoble' model (Rommelaere and Ritz 1996) and the 'Chicago1' model (MacAyeal and Thomas 1986) produced virtually no differences, and the comparison between the 'Grenoble' model and the 'Bremerhaven1' model (Huybrechts 1990) gave similar results as well. However, disagreements between 'Bremerhaven1' and 'Bremerhaven2' (Determann 1991) were evident, which is obviously due to the simplified dynamic equations of the latter model. The comparison of the modelled 'Chicago1' velocities with their observed counterparts showed that in fast-flowing regions the model overestimated the flow velocities significantly.

In this study, we apply the model FESSACODE described below (Sect. 2) to the 
Ross Ice Shelf, and investigate systematically the sensitivity of the ice flow to the main input parameters. This will give information as to how accurately the measured input data must be obtained to reasonably predict the thermomechanical response of the Ross Ice Shelf in particular and ice shelves in general. The parameter sensitivity tests are divided into the following parts:

- Flow enhancement factor.

- Ice thickness.

- Inflow velocity at the grounding line.

- Position of the grounding line of ice rises.

- Surface-temperature distribution.

- Ice-temperature profile.

In addition, we investigate the sensitivity of the ice flow to possible global warming in the future.

\section{Ice-shelf model FESSACODE}

FESSACODE (Finite Element Shallow-Shelf-Approximation Code) is a three-dimensional, dynamic/thermodynamic model for ice shelves developed by Weis (2001). In the present version, it solves diagnostically the elliptic boundary-value problem for the horizontal velocity in the shallow-shelf approximation (SSA). The deformation of ice is described by Glen's flow law (e.g. Paterson 1994),

$$
\mathbf{D}=E A(T) f(\sigma) \mathbf{t}^{\mathrm{D}}, \quad \text { with } f(\sigma)=\sigma^{n-1}, \quad n=3,
$$

where $\mathbf{D}=\operatorname{sym} \operatorname{grad} \mathbf{v}$ is the strain-rate tensor [symmetric part of the gradient of the velocity $\left.\mathbf{v}=\left(v_{x}, v_{y}, v_{z}\right)\right], \mathbf{t}^{\mathrm{D}}$ the Cauchy stress deviator, $\sigma=\left[\operatorname{tr}\left(\mathbf{t}^{\mathrm{D}}\right)^{2} / 2\right]^{1 / 2}$ the effective stress, $n$ the stress exponent, $T$ the absolute temperature, $A(T)$ the flow-rate factor (see below) and $E$ the flow enhancement factor.

Insertion of the flow law (1) in the SSA limit of the horizontal force balance yields the 
elliptic differential equations for the horizontal velocity $\left(v_{x}, v_{y}\right)$ (see Weis et al. 1999),

$$
\begin{aligned}
& 2 \frac{\partial}{\partial x}\left(\bar{\nu} \frac{\partial v_{x}}{\partial x}\right)+\frac{\partial}{\partial x}\left(\bar{\nu} \frac{\partial v_{y}}{\partial y}\right)+\frac{1}{2} \frac{\partial}{\partial y}\left[\bar{\nu}\left(\frac{\partial v_{x}}{\partial y}+\frac{\partial v_{y}}{\partial x}\right)\right]=\varrho H \frac{\partial H}{\partial x}+\frac{\tau_{x}^{\mathrm{d}}}{\rho g} \\
& \frac{\partial}{\partial y}\left(\bar{\nu} \frac{\partial v_{x}}{\partial x}\right)+2 \frac{\partial}{\partial y}\left(\bar{\nu} \frac{\partial v_{y}}{\partial y}\right)+\frac{1}{2} \frac{\partial}{\partial x}\left[\bar{\nu}\left(\frac{\partial v_{x}}{\partial y}+\frac{\partial v_{y}}{\partial x}\right)\right]=\varrho H \frac{\partial H}{\partial y}+\frac{\tau_{y}^{\mathrm{d}}}{\rho g}
\end{aligned}
$$

where the coordinates $x$ and $y$ span the horizontal plane, $\bar{\nu}$ is the effective viscosity, $\varrho=\left(\rho_{\mathrm{sw}}-\rho\right) / \rho_{\mathrm{sw}}$ the relative density $\left(\rho\right.$ : density of ice, $\rho_{\mathrm{sw}}$ : density of sea water), $H$ the ice thickness, $g$ the gravity acceleration, and $\tau_{x, y}^{\mathrm{d}}$ the basal drag in the $x$ and $y$ directions. The latter is set to zero for the floating ice shelf, but can be assigned non-vanishing values for grounded ice rumples (not done in this study). For the effective viscosity,

$$
\bar{\nu}=\frac{1}{\rho g} d^{\frac{1-n}{n}} \int_{h_{\mathrm{b}}}^{h_{\mathrm{s}}} E_{\mathrm{s}} B(T) d z,
$$

where $z$ is positive upward, $E_{\mathrm{s}}=E^{-1 / n}$ is the stress enhancement factor, $B(T)=$ $[A(T)]^{-1 / n}$ the associated rate factor, $h_{\mathrm{s}}$ and $h_{\mathrm{b}}$ are the positions of the free surface and the base (ice-ocean interface), respectively (ice thickness $H=h_{\mathrm{s}}-h_{\mathrm{b}}$ ), and

$$
d=\sqrt{\left(\frac{\partial v_{x}}{\partial x}\right)^{2}+\left(\frac{\partial v_{y}}{\partial y}\right)^{2}+\frac{\partial v_{x}}{\partial x} \frac{\partial v_{y}}{\partial y}+\frac{1}{4}\left(\frac{\partial v_{x}}{\partial y}+\frac{\partial v_{y}}{\partial x}\right)^{2}}
$$

is the effective strain rate (second invariant of the strain-rate tensor). For the associated rate factor $B(T)$, the relation by Hooke (1981) is employed,

$$
B(T)=B_{0} \exp \left(\frac{T_{0}}{T}-\frac{C}{\left(T_{\mathrm{r}}-T\right)^{k}}\right),
$$

with the parameters $B_{0}=6.984 \times 10^{-6} \mathrm{kPas}^{1 / 3}, T_{0}=3155 \mathrm{~K}, T_{\mathrm{r}}=273.39 \mathrm{~K}, k=1.17$ and $C=0.16612 \mathrm{~K}^{k}$.

The elliptic system of differential equations (2) is subject to two different types of boundary conditions: (i) Inflow of ice along the grounding line from the adjacent inland ice, and (ii) a vertically integrated stress boundary condition at the front edge. Further, the ice-thickness distribution $H(x, y)$ and the temperature field $T(x, y, z)$ must be prescribed.

The $\mathrm{C}^{++}$program FESSACODE solves the above boundary-value problem by employing the finite element technique, similar to the 'Chicago1' model mentioned in the introduction. Numerical determination of the velocity field is accomplished by an itera- 
tive integration procedure. This iteration is needed because of the non-linear flow law (1) and encompasses a sequential updating of the effective viscosity (3). Experience gained so far has shown that usually a few iterations are sufficient for proper convergence. The performance of FESSACODE was verified by applying it to a simple, "academic" problem for which an exact analytical solution exists (Weis 2001). Furthermore, due to its well-structured class architecture FESSACODE is open to extensions like the inclusion of prognostic equations for the ice thickness and the temperature, local ice weakening in crevassed areas etc.

The standard values of the relevant physical parameters used for the simulations herein are listed in Table 1.

\begin{tabular}{ll}
\hline Quantity & Value \\
\hline Gravity acceleration, $g$ & $9.81 \mathrm{~m} \mathrm{~s}^{-2}$ \\
Density of ice, $\rho$ & $910 \mathrm{~kg} \mathrm{~m}^{-3}$ \\
Density of sea water, $\rho_{\mathrm{sw}}$ & $1028 \mathrm{~kg} \mathrm{~m}^{-3}$ \\
Power-law exponent, $n$ & 3 \\
Stress enhancement factor, $E_{\mathrm{s}}$ & 0.86 \\
\hline
\end{tabular}

Table 1: Standard physical parameters of the ice-shelf model.

\section{Simulation set-up}

The model domain for the simulations of this study is the entire area of the Ross Ice Shelf. Ice thickness is derived from the BEDMAP Digital Terrain Model (DTM) for Antarctica, which was processed from field survey data collected over the past 50 years and has a grid size of $5 \mathrm{~km}$ (Lythe et al. 2000). Figure 2a shows the distribution of the ice thickness, which is in general largest at the Siple Coast grounding line and decreases towards the calving front. The grounding-line position has been derived by the authors by using the water column below the ice, the ice thickness and the hydrostatic equilibrium. These three quantities were combined in a way to minimize the remaining mismatch. Great care was required in the vicinity of the Transantarctic Mountains where very large changes of the ice-shelf thickness over short distances occur. The procedure is described in more detail by Humbert (2004).

The applied inflow velocities at the grounding line are listed in Table 2 (see also Fig. 1). At the margins of Roosevelt Island and Crary Ice Rise we impose a no-slip boundary condition (van der Veen 1999) and neglect the outflow into the ice shelf. The latter is justified because the measured outflow at Roosevelt Island is at most $30 \mathrm{~m} \mathrm{a}^{-1}$ (Sanderson 1979). 

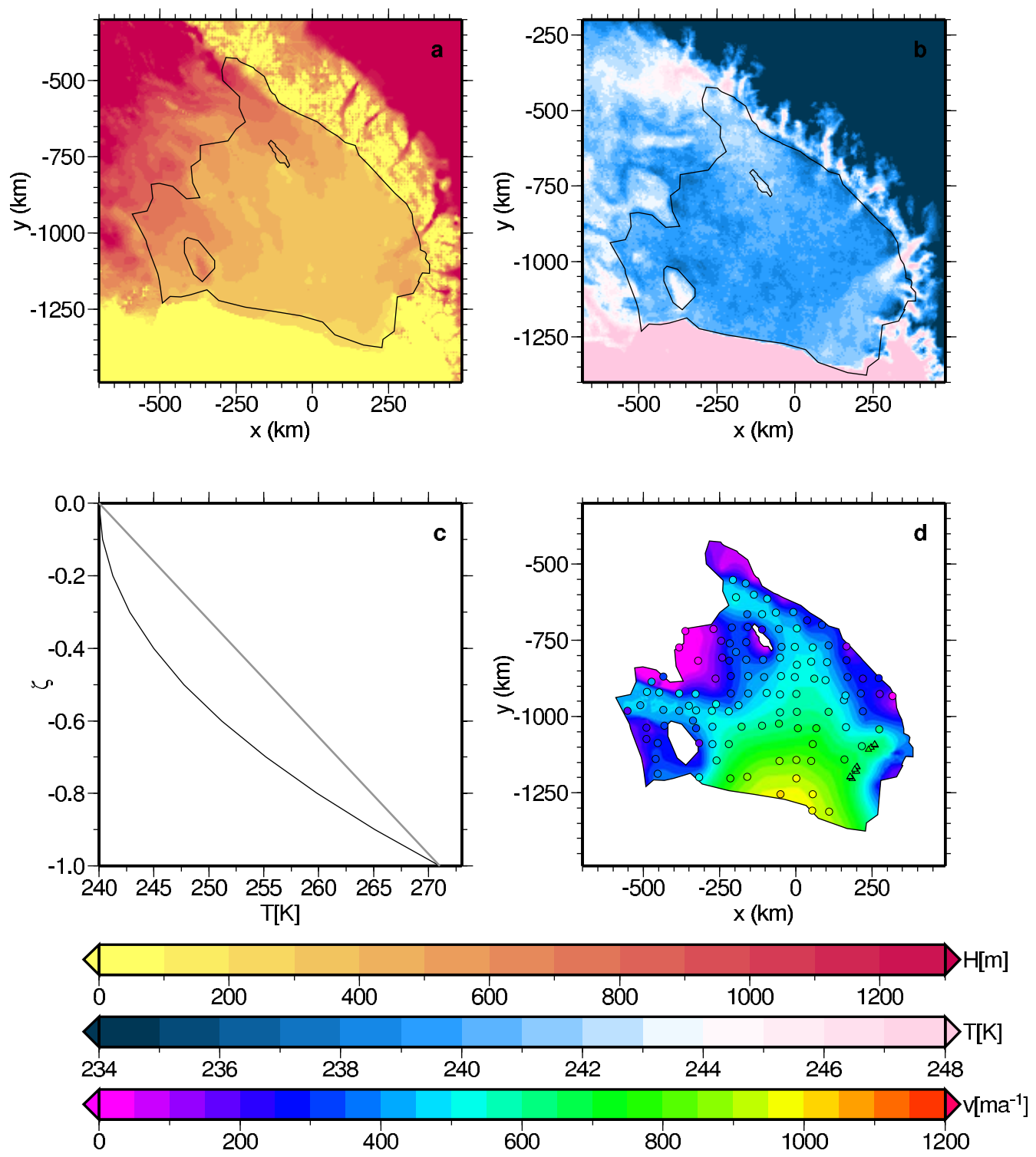

Figure 2: Data for the Ross Ice Shelf. (a) Ice thickness $H$ by Lythe et al. (2000). (b) Surface temperature $T_{\mathrm{s}}$ by Humbert and Scambos (2005). (c) Parabolic [Eq. (8)] and linear [Eq. (12)] temperature profile $T(\zeta)$ for $T_{\mathrm{s}}=240 \mathrm{~K}, T_{\mathrm{b}}=271 \mathrm{~K}$ and $H=$ $400 \mathrm{~m}$. (d) Surface speed $v$ by Thomas et al. (1984) (RIGGS data, coloured dots), complemented by satellite image velocities (Bindschadler and Scambos 1991, Scambos et al. 1992, Bindschadler et al. 1996, 1997) and interpolated to the entire ice-shelf area (coloured contours).

The ice surface temperature shown in Fig. 2b was obtained by applying a new cloud detection algorithm based on image-to-image correlation to AVHRR temperature data of the year 1992. The algorithm, the analysis and the results are discussed in detail in Humbert and Scambos (2005). The ice surface temperature shows a larger spatial variablity than to be expected from temperature data of Antarctic weather stations and 


\begin{tabular}{rlrc}
\hline No. & Ice stream, glacier & $\begin{array}{r}\text { Velocity } \\
\left(\mathrm{m} \mathrm{a}^{-1}\right)\end{array}$ & $\begin{array}{r}\text { Volume flux } \\
\left(\mathrm{km}^{3} \mathrm{a}^{-1}\right)\end{array}$ \\
\hline 1 & Prestrud Inlet & 200 & 1.85 \\
2 & Echelmeyer Ice Stream & 640 & 6.16 \\
3 & MacAyeal and Bindschadler Ice Streams & $680 / 640$ & $38.11^{\mathrm{b}}$ \\
4 & Whillans and van der Veen Ice Streams & $400 / 400$ & $33.9^{\mathrm{b}}$ \\
5 & Scott Glacier & 450 & 2.01 \\
6 & Amundsen Glacier & 700 & 1.9 \\
7 & Liv Glacier & 480 & 0.55 \\
8 & Shackleton Glacier & 280 & 0.99 \\
9 & Beardmore Glacier & 700 & 3.99 \\
10 & Nimrod Glacier & 550 & 1.84 \\
11 & Byrd Glacier & 1200 & 16.93 \\
12 & Darwin Glacier & 350 & 1.03 \\
13 & Mulock Glacier & 550 & 2.1 \\
14 & Skelton Glacier & 350 & 1.34 \\
\hline
\end{tabular}

Table 2: Inflow at the grounding line $\mathrm{e}^{\mathrm{a}}$.

a Sources: Weis (2001), Humbert (2004) and references therein. ${ }^{\mathrm{b}}$ Total volume flux of both ice streams.

10 m temperature data recorded by Crary et al. (1962), Crary (1963), Thomas et al. (1984).

The temperature profile recorded at the Little America V (LAV) Station by Gow (1963) shows a parabolic dependence between temperature and depth. In contrast, Clough and Hansen (1979) obtained a linear temperature profile and marine ice layer of $6 \mathrm{~m}$ thickness at station J9. The process of marine-ice accretion has a direct influence on the temperature profile, as deduced by analysis of the heat transport equation by Shumskiy and Krass (1976). Radio echo soundings (Neal 1979) and studies of bottom mass balance rates (Thomas 1978, Shabtaie and Bentley 1979) gave evidence that at the ice/ocean interface of the Ross Ice Shelf mainly melting conditions prevail (in contrast to the Hells Gate, Amery and Filchner-Rønne Ice Shelves). Assuming a LAV-type parabolic temperature profile for the entire ice shelf is therefore well justified. An analysis of simulations using different scenarios of spatial melting/freezing distributions can be found in Humbert (2004).

In order to derive a LAV-type temperature profile applicable to the entire ice shelf, we define a normalized vertical coordinate $\zeta$ and a normalized temperature $\Theta$ by

$$
\begin{aligned}
\zeta & =-\frac{h_{\mathrm{s}}-z}{h_{\mathrm{s}}-h_{\mathrm{b}}}, \\
\Theta & =-\frac{T_{\mathrm{b}}-T}{T_{\mathrm{b}}-T_{\mathrm{s}}},
\end{aligned}
$$


so that $\zeta=0$ corresponds to the ice-shelf surface $z=h_{\mathrm{s}}, \zeta=-1$ to the ice-shelf base $z=h_{\mathrm{b}}, \Theta=-1$ to the surface temperature $T=T_{\mathrm{s}}$ and $\Theta=0$ to the basal temperature $T=T_{\mathrm{b}}$. The latter is assumed to be equal to the freezing temperature $T_{\mathrm{f}}$ of the ocean water below the ice shelf,

$$
T_{\mathrm{f}}=-0.036-0.00759 P-0.0499 S-0.000112 S^{2},
$$

where $T_{\mathrm{f}}$ is in ${ }^{\circ} \mathrm{C}, P$ is the hydrostatic pressure in bar and $S$ the salinity in ppt (Fujino et al. 1974). For the latter we use the fixed value $S=34.6 \mathrm{ppt}$. The general form of a parabolic temperature profile which fulfills the boundary conditions at the surface $[\Theta(0)=-1]$ and the base $[\Theta(-1)=0]$ is then given by

$$
\Theta(\zeta)=a \zeta^{2}+(a-1) \zeta-1
$$

The parabolic fit $T(\zeta)=251.08+6.19 \zeta+24.18 \zeta^{2}(T$ in $\mathrm{K})$ to the temperature profile of the LAV station (Humbert 2004) corresponds to $a=1.34408$ in Eq. (8). However, this fit shows a slight inversion in the uppermost part of the ice column which is neither corroborated by the LAV data themselves nor by measured profiles at other locations (Humbert 2004, and references therein). Therefore, we choose $a=1$, which removes the inversion and yields a vertical tangent to the temperature profile at the ice surface. As an example, Fig. $2 \mathrm{c}$ shows the temperature profile (8) for $T_{\mathrm{s}}=240 \mathrm{~K}, T_{\mathrm{b}}=271 \mathrm{~K}$ and $H=400 \mathrm{~m}$, which represents closely the conditions in the central part of the ice shelf. (The figure shows also the linear profile which will be used for comparison in Sect. 5.5.)

An alternative way of determining the temperature profiles would be to employ the analytical representations by Zotikov (1986). However, these functions are based on the assumptions of negligible horizontal flow and constant ice thickness, and they require the knowledge of the surface and bottom accumulation and melting rates, information about which is largely lacking. Because of these problems, our extrapolation of measured profiles to the entire ice shelf and an attempt to apply Zotikov's [1986] analytical profiles are at least on a par.

The measured ice-shelf flow is shown in Fig. 2d. The interpolation on the entire region of the Ross Ice Shelf is based on field measurements from the RIGGS campaign (Thomas et al. 1984, denoted as circles in the picture) as well as satellite image velocities by Bindschadler and Scambos (1991), Scambos et al. (1992), Bindschadler et al. (1996, 1997). Since the spatial distribution of the ice flow is the main output of the model FESSACODE, these data will be used to validate our simulation results.

The triangular mesh has been created such that the locations of RIGGS stations fall 
together with nodes of the mesh, which facilitates comparison between measured and simulated velocities. It consists of 2290 elements with 1398 nodes, and the size of the elements varies from $0.71 \mathrm{~km}$ to $49.8 \mathrm{~km}$ (minimum and maximum side length, resp.) depending on the position in the ice shelf (Fig. 3). The number of iterations is fixed to 100, which has been found to ensure proper convergence for all simulations.

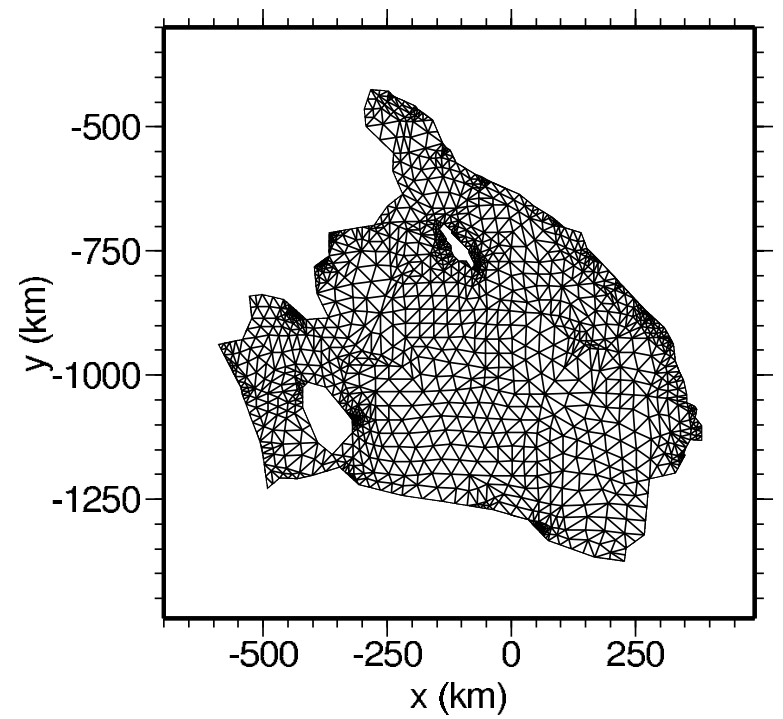

Figure 3: Triangular mesh created by using the ice-velocity data of the RIGGS campaign (Fig. 2d) as nodes.

\section{Reference simulation}

The above-described settings (Sect. 3) together with the physical parameters listed in Table 1 define the reference simulation REF. The stress enhancement factor $E_{\mathrm{s}}$ is chosen such that the absolute value of the mean difference between measured RIGGS ( $v_{\text {RIGGS }}$ ) and simulated $\left(v_{\mathrm{REF}}\right)$ speeds is minimized,

$$
\left|\frac{1}{N} \sum_{n=1}^{N}\left(v_{\mathrm{RIGGS}, n}-v_{\mathrm{REF}, n}\right)\right| \stackrel{!}{=} \min ,
$$

where the index $n$ numbers the $N$ RIGGS-velocity data points (which fall together with the nodes of the numerical grid). This procedure yields the value $E_{\mathrm{s}}=0.86$ (corresponding to the flow enhancement factor $E=1.57$ ), for which the remaining mean difference is $+8.4 \mathrm{~m} \mathrm{a}^{-1}$.

The left panel of Fig. 4 shows the simulated velocity field in comparison to the RIGGS data points. In addition, in the right panel the simulated velocities are displayed vs. 

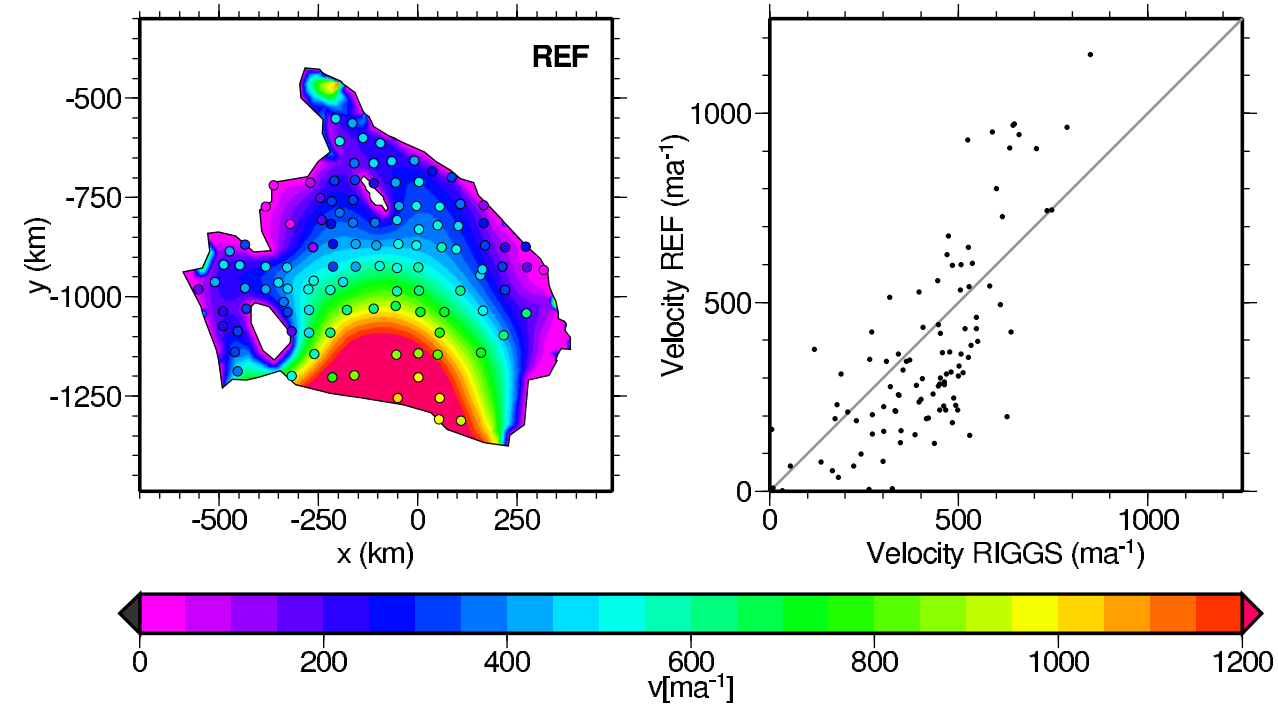

Figure 4: Left: Simulated speed distribution of the Ross Ice Shelf (coloured contours) for run REF. For comparison, the measured RIGGS speeds are displayed as dots with the same colour coding. Right: Scatter plot of simulated vs. RIGGS speeds.

the RIGGS velocities as a scatter plot. The general flow pattern and the magnitudes of the flow velocities are reproduced quite well. However, a systematic deviation becomes apparent in that the simulation tends to underestimate small and to overestimate large flow velocities. This is particularly noticeable for the two bands of ice which emanate from the MacAyeal/Bindschadler and Whillans/van-der-Veen ice-stream systems (very well visible as light-blue bands in Fig. 2d). These bands show measured flow velocities of $\sim 500 \mathrm{~m} \mathrm{a}^{-1}$ surrounded by slower-flowing ice and have no counterpart in the simulation results. To a lesser extent, this behaviour also holds for the region downstream of Byrd Glacier. On the other hand, velocities of the fast-flowing region upstream of the calving front between Roosevelt Island and the Transantarctic Mountains $\left(>800 \mathrm{~m} \mathrm{a}^{-1}\right.$ ) are generally overestimated by $\sim 20 \%$.

A number of reasons is conceivable for these discrepancies. The above-mentioned underestimated velocities downstream of the main inflow systems may be due to generally lower viscosities of heavily damaged ice originating from fast-flowing ice streams and glaciers. This effect may be further complicated by changing ice-stream activities in the past. For the narrows between Crary Ice Rise and the Transantarctic Mountains, a particular problem is that the BEDMAP ice-thickness data show numerous inconsistencies with the hydrostatic equilibrium and the water column below the ice (especially around the base of the Transantarctic Mountains), so that they are likely flawed. Of course, this influences the source terms in Eqs. (2) and leads to errors in the computed flow field. Another major source of disagreement is due to varying basal melting/freezing 
conditions which alter the temperature distribution in the ice shelf. Also, the local ice viscosity can be influenced by several types of impurities as well as anisotropic fabrics of the polycrystalline ice, about which little is known in detail. Therefore, Rommelaere and MacAyeal (1997) computed the distribution of the effective viscosity $\bar{\nu}$ inversely with a control method that aimed at minimizing the misfit between observed and simulated velocities. They limited their analysis to the central part of the ice shelf between the ice rises and the Transantarctic Mountains and found a complex viscosity pattern, the structure of which is only poorly correlated to the surface-temperature field of Fig. $2 \mathrm{~b}$ which determines our viscosity distribution. It is therefore clear that some structures of the flow field cannot be reproduced by our simulation.

We also investigate the net surface and bottom mass balance, $a_{\text {net }}$, required to compensate for dynamic thinning and preserve the present-day geometry of the ice shelf. It must balance the horizontal divergence of the volume flux,

$$
a_{\mathrm{net}}=-\left(\frac{\partial\left(H v_{x}\right)}{\partial x}+\frac{\partial\left(H v_{y}\right)}{\partial y}\right)
$$

Results are shown in Fig. 5. Evidently, the distribution is very patchy, and areas of positive and negative mass balances with values of tens of meters per year alternate. This is likely a consequence of fine-structure inaccuracies of the simulated flow field and therefore of limited significance. More interesting is the average mass balance for the entire ice shelf, which balances globally the inflow at the grounding line and the outflow at the calving front. It is $+1.374 \mathrm{~m} \mathrm{a}^{-1}$, which means that the ice shelf requires a continuous supply of ice of this rate in order to preserve its total volume. Alternatively interpreted, if the overall mass balance were equal to zero, the ice shelf would be thinning on average at this rate.

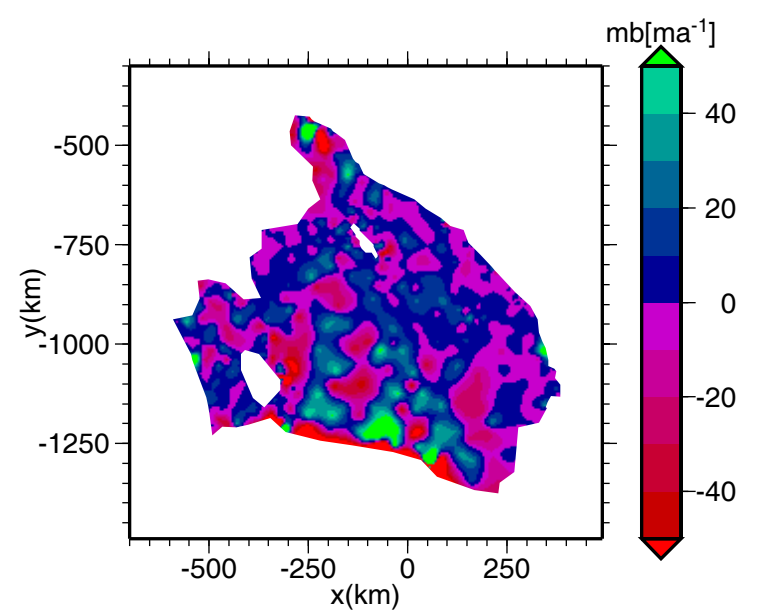

Figure 5: Steady-state mass balance of the Ross Ice Shelf for the reference run REF. 


\section{Parameter studies}

\subsection{Sensitivity to the enhancement factor}

As described above, the reference value of the stress enhancement factor, $E_{\mathrm{s}}=0.86$, was determined by minimizing the disagreement between simulated and measured (RIGGS) flow velocities. In order to demonstrate the influence of $E_{\mathrm{s}}$ on the ice flow, we have conducted two simulations with varied values of $E_{\mathrm{s}}$. For simulation ES058, $E_{\mathrm{s}}=0.58$ is chosen. This corresponds to the flow enhancement factor $E=5$, a value which is commonly used in simulations of the Antarctic inland ice sheet (e.g. Huybrechts 1992, Savvin et al. 2000). Simulation ES100 is carried out with $E_{\mathrm{s}}=E=1$, which is the value for pure isotropic ice.

As expected, the dependency of the simulated velocities on the value of $E_{\mathrm{s}}$ is very strong. Fig. 6 displays the velocity fields for simulations ES058 and ES100, compares them to the RIGGS data points (left panels) and also to those of simulation REF at each RIGGS station (right panels). Evidently, simulation ES058 produces too large velocities for the entire ice shelf. By contrast, for simulation ES100 the agreement to the RIGGS data is even better than for simulation REF in the fast-flowing region upstream of the calving front between Roosevelt Island and the Transantarctic Mountains, but at the cost of too slow ice flow in the other parts of the ice shelf. The scatter plots (right panels) reveal that most of the simulated velocities lie very close to a straight line, the slope of which is equal to the ratio of the flow enhancement factors $E$, that is, $5: 1.57=3.18$ for simulation ES058 and $1: 1.57=0.64$ for simulation ES100. In other words, the simulated velocities scale directly with the flow enhancement factor. Natural exceptions from this rule are the velocities at or very close to the grounding line, which are less affected by the enhancement factor because they are mainly determined by the (unchanging) inflow boundary condition. These findings already suggest that, apart from a small boundary zone around the grounding line, the ice flow is essentially unaffected by the inflow from the ice streams and glaciers. We will investigate this in more detail below (see Sect. 5.3).

\subsection{Sensitivity to the ice thickness}

We now investigate the sensitivity of the simulated velocity distribution to variations of the ice thickness. To this end, the thickness is multiplied with a scale factor $f$, which leads to a change of the right-hand sides (source terms) of Eqs. (2) as follows:

$$
H \frac{\partial H}{\partial x}, H \frac{\partial H}{\partial y} \rightarrow f H \frac{\partial(f H)}{\partial x}, f H \frac{\partial(f H)}{\partial y} .
$$



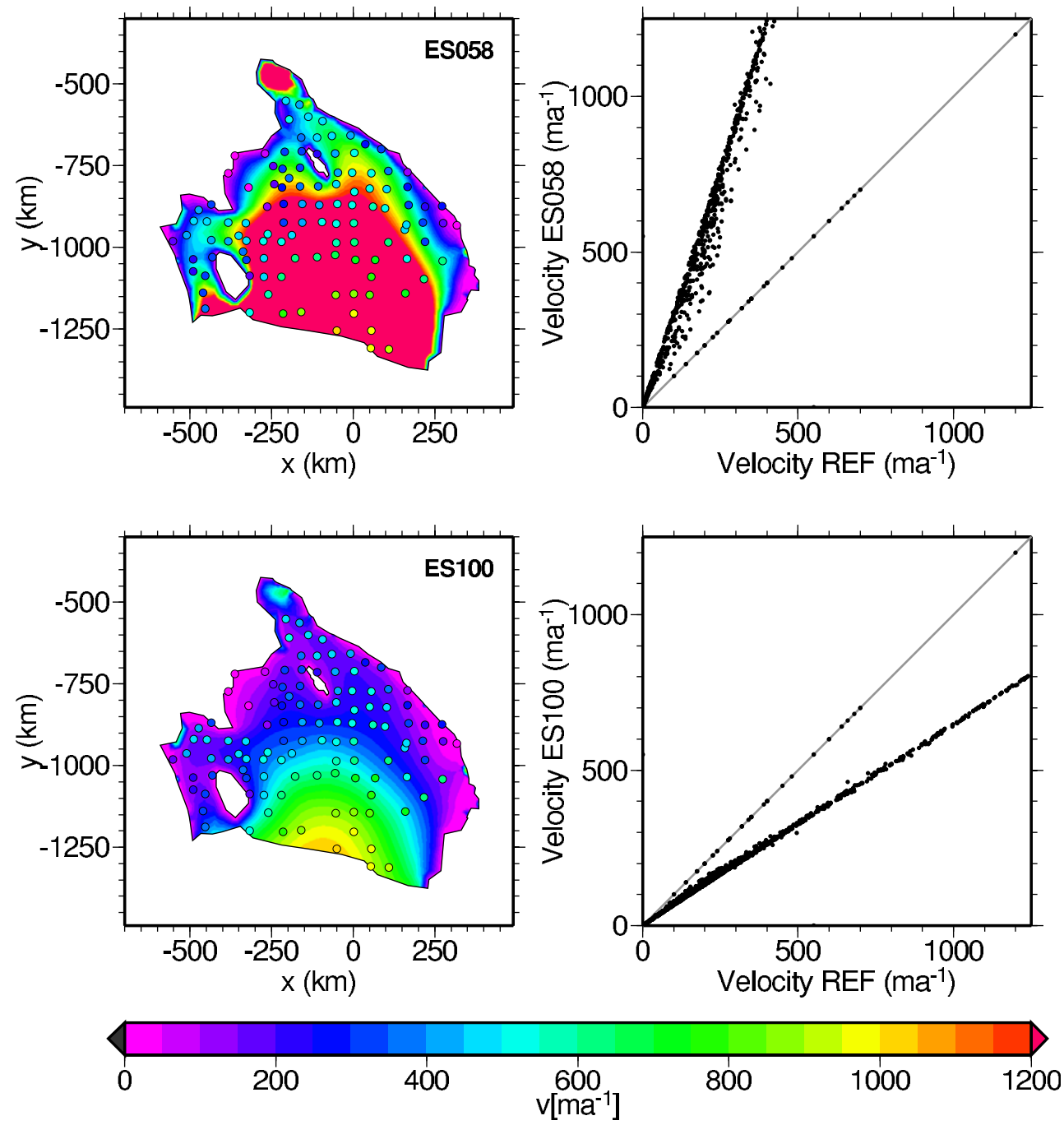

Figure 6: Left: Simulated speed distributions of the Ross Ice Shelf (coloured contours) for runs ES058 and ES100 (varied enhancement factor). For comparison, the measured RIGGS speeds are displayed as dots with the same colour coding. Right: Scatter plots of speeds simulated by runs ES058 and ES100 vs. speeds simulated by run REF.

Note that the effect of the scale factor $f$ in (11) is quadratic.

Two simulations were run. For simulation IT080, the scale factor $f$ was set to 0.8 , whereas for simulation IT120 $f=1.2$ was chosen. Results are shown in Fig. 7. It is evident that the sensitivity of the simulated ice flow to the assumed ice-thickness changes is comparable to that of the enhancement-factor changes discussed above. Again, in the scatter plots for the simulated velocities versus their reference counterparts, most points lie close to a straight line, except for those of the grounding-line boundary zone. For simulation IT080, the slope is $0.8^{3}=0.51$, and for simulation IT120, it is $1.2^{3}=1.73$, so that the velocities scale apparently with the third power of the thickness scale factor.

This can be understood as follows. Let $k$ be the unknown scale factor for $v_{x}, v_{y}$ and $d$, 

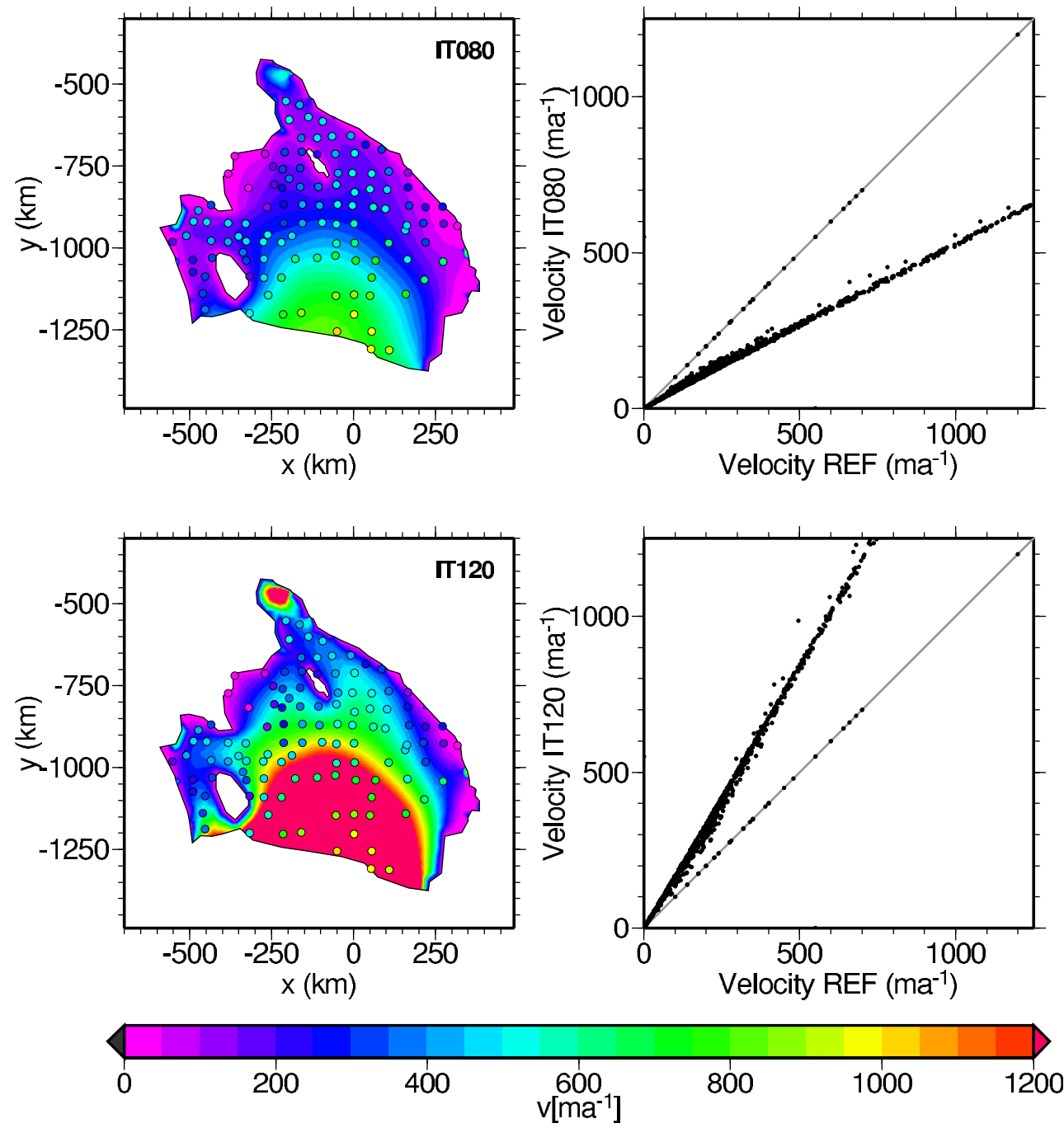

Figure 7: Same as Fig. 6, but for simulations IT080 and IT120 (varied ice thickness).

then the effective viscosity $\bar{\nu}$ scales with $k^{(1-n) / n} f$ [see Eq. (3); unchanged temperature conditions assumed]. Therefore, the left-hand sides of Eqs. (2) scale with $k^{(1-n) / n} f k=$ $k^{1 / n} f$, and the scale for the right-hand sides is $f^{2}$ [see Eq. (11)]. Since the scale for both sides must be equal, $k^{1 / n} f=f^{2}$, which leads to $k=f^{n}$, so that with $n=3$ the cubic velocity scale factor is explained. However, this argument holds only as long as the influence of the fixed boundary conditions is negligible, and consequently the velocities in the boundary zone around the grounding line are affected to a lesser extent.

The strong dependency of the ice flow on the ice-thickness input shows that an accurate data-base for the ice-thickness distribution is crucial for any reasonable studies of ice-shelf dynamics. This statement relates not only to the quality of the raw data, but also to the use of sophisticated techniques like kriging (Herzfeld et al. 2000) for interpolating the data on a numerical grid. 


\subsection{Sensitivity to the inflow velocity at the grounding line}

The results of Sects. 5.1 and 5.2 have indicated that, except for a narrow boundary zone along the grounding line, the flow velocities of the Ross Ice Shelf are essentially unaffected by the inflow velocity of the ice streams and glaciers. Now we perform a direct test of this finding by changing the prescribed inflow velocities. In simulation VS000, zero inflow is assumed, whereas for simulation VS200 all inflow velocities and volume fluxes are doubled. Since these tests do not distinguish between ice streams and glaciers, the relative importance of the large inflow from the Siple Coast ice streams and the smaller inflow from the Transantarctic Mountains is preserved.
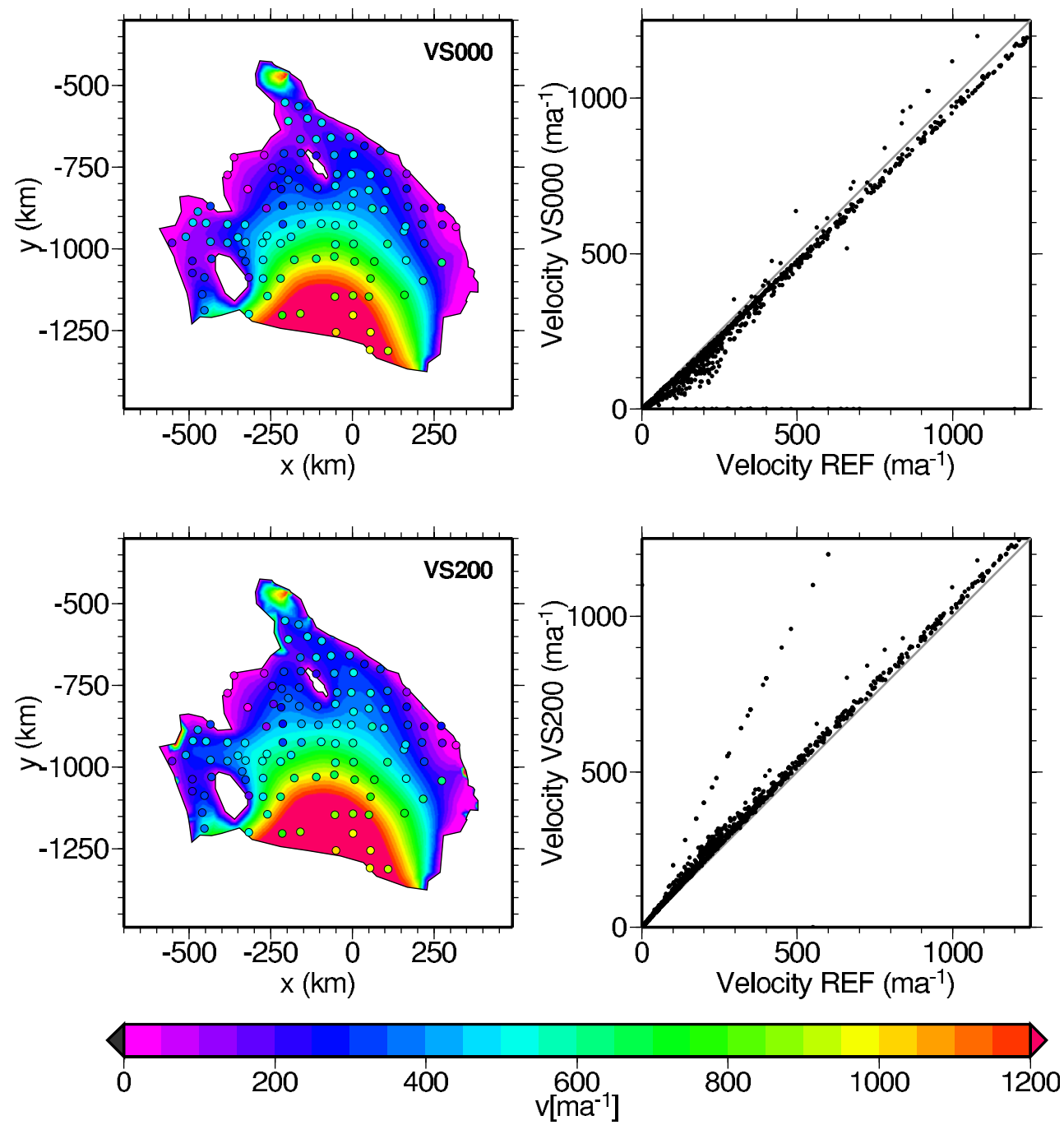

Figure 8: Same as Fig. 6, but for simulations VS000 and VS200 (varied grounding-line inflow).

Even though these two scenarios are extreme cases, the results shown in Fig. 8 demonstrate that the influence on the ice flow is indeed negligible for most parts of the ice 
shelf. A few subtle differences between the flow fields of the two simulations discernible in the contour plots (left panels) are limited to areas $\sim 20 \mathrm{~km}$ downstream of the three main inflow systems (MacAyeal/Bindschadler ice streams, Whillans/van der Veen ice streams, Byrd glacier). These areas are reflected in the scatter plots (right panels) as points with almost zero velocity (simulation VS000) and points with almost double velocity (simulation VS200). However, the majority of simulated velocity values in the interior of the ice shelf is only decreased (simulation VS000) or increased (simulation VS200) by a few percent compared to simulation REF.

Consequently, it is confirmed that the direct sensitivity of the velocity field to the inflow velocities at the grounding line is very small everywhere in the ice shelf except for the immediate vicinity of the main inflow systems. Of course, the validity of this statement is limited to the diagnostic analysis of a given time-slice with prescribed ice thickness. In the course of time, inflow from the grounding line is a major factor which controls the evolution of the ice-shelf thickness, and therefore the velocity field.

The above results can directly be transferred to the inflow from the ice rises. We have performed an additional simulation in which the inflow from Roosevelt Island and Crary Ice Rise was changed from zero (reference case) to $50 \mathrm{~m} \mathrm{a}^{-1}$, which is distinctly larger than the measured values of $\leq 30 \mathrm{~m} \mathrm{a}^{-1}$ for Roosevelt Island (Sanderson 1979). The results (not shown) confirm that the influence on the flow field of the ice shelf is negligibly small.

\subsection{Sensitivity to the position of the grounding line of the ice rises}

In order to assess the role of the ice rises for the stability of the Ross Ice Shelf, we now discuss the two simulations GL10 and GL20, for which the grounding lines of Roosevelt Island and Crary Ice Rise have been shifted by $10 \mathrm{~km}$ and $20 \mathrm{~km}$, respectively, in normal direction into the surrounding ice shelf (that is, the areas of the ice rises are increased). Fig. 9 displays the results.

Considering that the enlargement of the ice rises is rather small and of local nature, the effect on the flow velocities is surprisingly pronounced in the entire ice-shelf area. On average, the velocities shown in the scatter plots (right panels) are decreased by $10.2 \%$ for run GL10 and $18.8 \%$ for run GL20. This underlines the non-local behaviour of the governing equations (2), and is in strong contrast to the local nature of ice-sheet dynamics

(e.g. Hutter 1983, Baral et al. 2001). The reason is, of course, the ellipticity of the former against the parabolicity and hyperbolicity of the latter equations. Nevertheless, the impact is strongest in the vicinity of the ice rises, as it becomes most evident for the 

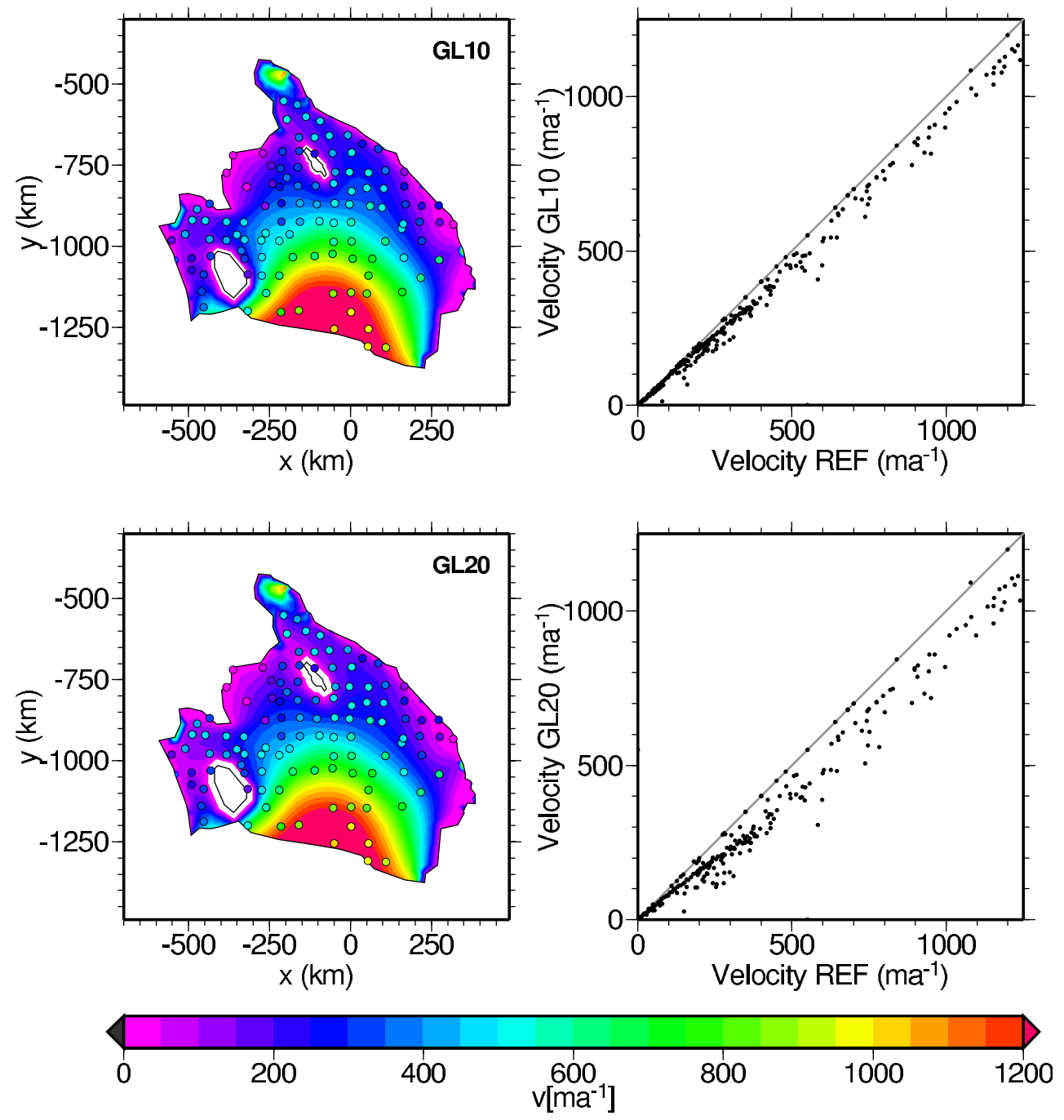

Figure 9: Same as Fig. 6, but for simulations GL10 and GL20 (varied position of the grounding line of the ice rises).

narrows between the two ice rises and the adjacent stretches of the Siple Coast (see left panels of Fig. 9). In these areas, the boundary shift of the ice rises effectively increases the side drag in the remaining floating ice, which leads to a strong slowdown of the ice flow.

The results of these sensitivity tests indicate that the ice rises play an important role for the stability of the ice shelf as a whole by efficiently slowing down the coastward ice flow. Therefore, a loss of contact between the ice shelf and the ice rises, for instance by heavy crevassing of the transition zone, may be a serious threat to the further stability of the Ross Ice Shelf. 


\subsection{Sensitivity to the surface-temperature distribution and to the ice-temperature profile}

Since the rate factors $A(T)$ and $B(T)$ show a strong dependence on temperature (Sect. 2), it is clear that ice temperature plays an important role in determining the flow of the Ross Ice Shelf. In order to quantify this issue, for simulation PST the detailed surface-temperature distribution described in Sect. 3 has been replaced by the simple parametrization given by King and Turner (1997, Table 3.5 on p. 83), $T_{\mathrm{s}}=49.642-$ $0.943 \varphi$ [where $T_{\mathrm{s}}$ is the surface temperature in ${ }^{\circ} \mathrm{C}$ and $\varphi$ the latitude in ${ }^{\circ} \mathrm{S}$; see also Fortuin and Oerlemans (1990)]. In a further simulation (run LTP) the parabolic temperature profile (12) has been replaced everywhere by the linear profile

$$
\Theta(\zeta)=-\zeta-1
$$

which can be obtained by setting $a=0$ in Eq. (8) (see Fig. 2c).

Results are shown in Fig. 10. For both simulations, the average temperature of the ice shelf is increased which makes the ice softer and increases the flow velocities. The effect is equally pronounced for both simulations and shows an increase of most of the simulated velocities by about a factor two, with some more variety in simulation PST. This strong dependency underlines the utmost importance of a careful treatment of the surface-temperature input as well as the determination of the temperature field in the ice shelf for studies on ice-shelf dynamics. However, it is also clear that uncertainties associated with the rate factors $A(T)$ and $B(T)$ themselves (e.g. van der Veen 1999) limit the accuracy of computed velocity fields from the outset.

\section{Impact of global warming}

Mainly as a consequence of anthropogenic emissions of greenhouse gases since the beginning of the industrial revolution (approximately 1750 AD), the Earth's lower atmosphere experiences an ongoing warming. The globally averaged surface-temperature increased by $0.6 \pm 0.2 \mathrm{~K}$ during the 20th century, and is predicted to increase further by 1.4 to $5.8 \mathrm{~K}$ over the period 1990 to 2100 (Houghton et al. 2001). The warming is likely to be more pronounced over land masses and in northern high latitudes (Cubasch et al. 2001). Kwok and Comiso (2002) analyzed the surface-temperature trend over Antarctica for the period 1982-1998 and concluded that during that time much of East Antarctica experienced a cooling against the global trend, whereas the peripheral seas showed a strong warming due to decreasing sea ice extent. For most parts of the Ross and Filchner-Rønne 

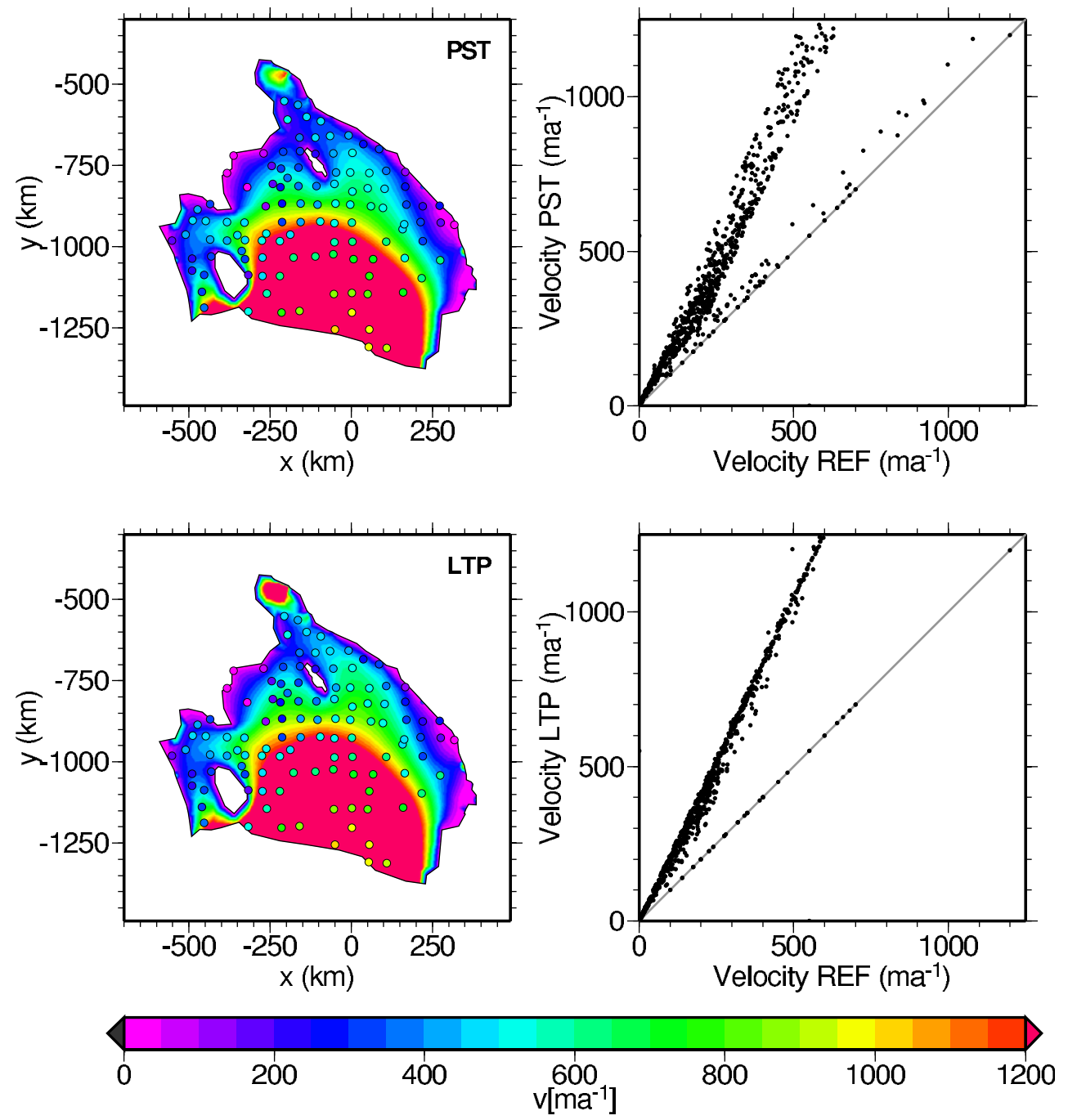

Figure 10: Same as Fig. 6, but for simulations PST (varied surface-temperature distribution) and LTP (varied ice-temperature profile).

Ice Shelves moderate warming is reported.

Therefore, we now investigate the response of the Ross Ice Shelf to a prescribed surface warming. In reality, global warming will likely lead to spatially non-uniform surface-temperature changes; however, within the frame of this fundamental, diagnostic study we restrict ourselves to simple scenarios with spatially uniform warmings. Five simulations (GW02, GW04, GW06, GW08, GW10) are conducted, for which a surfacetemperature increase of $\Delta T=2 \mathrm{~K}, 4 \mathrm{~K}, 6 \mathrm{~K}, 8 \mathrm{~K}$ and $10 \mathrm{~K}$, respectively, is assumed (Table 3). The results of the simulations are depicted in Fig. 11.

As observed in the parameter studies discussed above, the entire area of the ice shelf except a narrow zone around the grounding line reacts very strongly to the altered boundary conditions. Most velocity points shown in the scatter plot scale by an almost constant factor with respect to the simulation REF. This scale factor increases from 


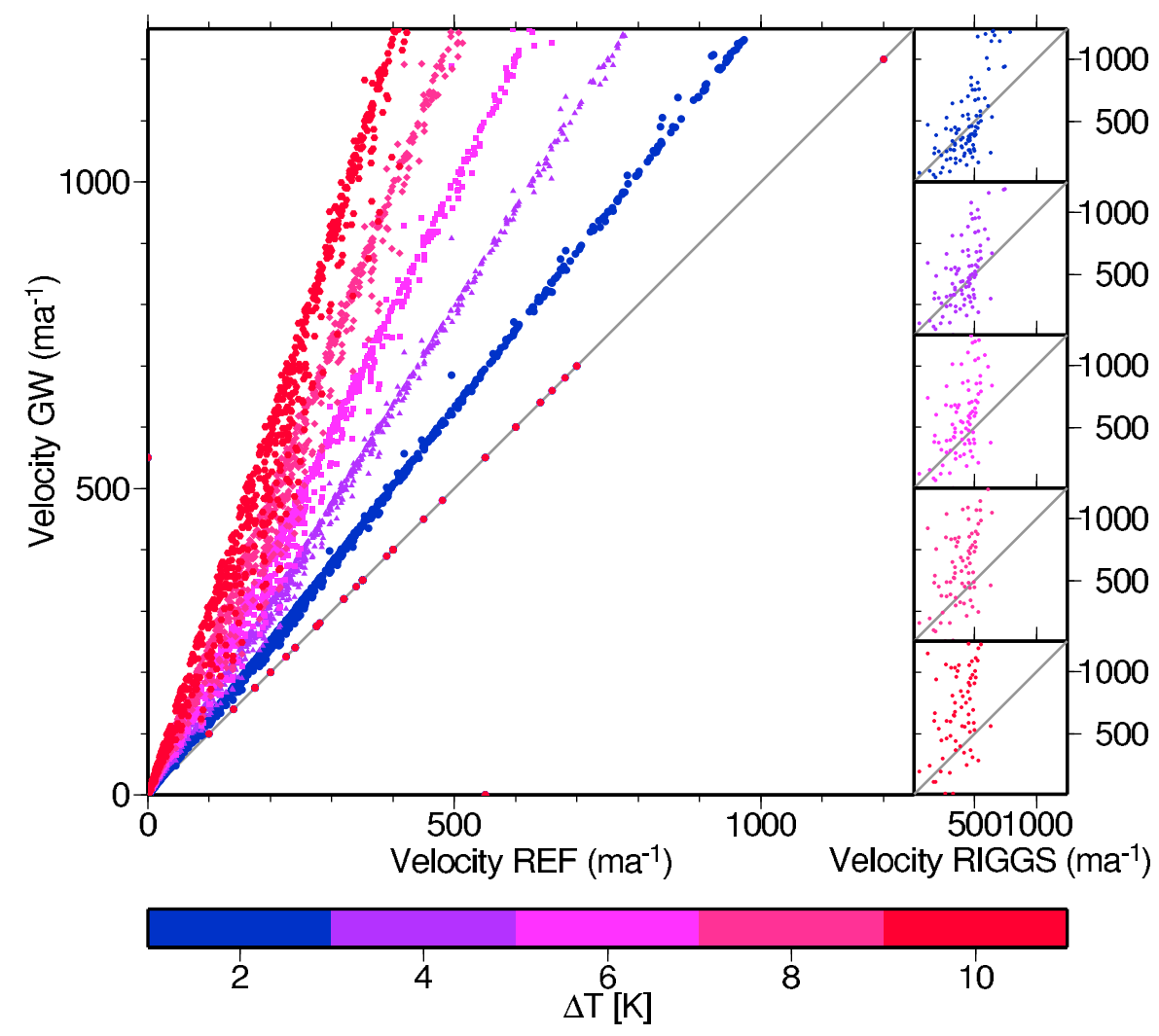

Figure 11: Impact of global warming on the flow of the Ross Ice Shelf. The large panel displays the simulated velocities of runs GW02 (warming of $\Delta T=2 \mathrm{~K}$ ), GW04 $(4 \mathrm{~K}$ ), GW06 (6 K), GW08 (8 K) and GW10 (10 K) vs. those of the reference run REF. The insets show the simulated velocities of these runs vs. the RIGGS velocities.

$\sim 1.25$ for simulation GW02 to $\sim 3.1$ for simulation GW10. Therefore, the Ross Ice Shelf is quite vulnerable to a moderate surface-temperature increase in the range of several degrees, which may occur during this century as a consequence of global warming.

We also investigate the average mass balance of the ice shelf (see above, last paragraph of Sect. 4) which results from the enhanced ice flow. Results are shown in Fig. 12. Evidently, the mass balance becomes significantly more positive with increasing surface temperature, and the ratio to the mass balance of simulation REF is almost equal to the scale factors for the ice flow discussed above (which is not clear from the outset because the inflow at the grounding line is kept constant). It is not likely that this strongly increased mass balance can be sustained by increased precipitation and/or basal freezing. Therefore, global-warming conditions will lead to a significant thinning of the ice shelf in the course of time, and increase the probability for major break-up events or even disintegration of large parts of the ice shelf. Since in Sect. 5.4 the important stabilizing effect of the ice rises has become evident, a positive feedback mechanism may even worsen the situation. Accelerated ice flow due to global warming may lead to 
enhanced crevassing around the grounding line of the ice rises, therefore the side drag will be reduced (note that we have assumed no-slip conditions at the margin of the ice rises) and the ice flow accelerated even more.

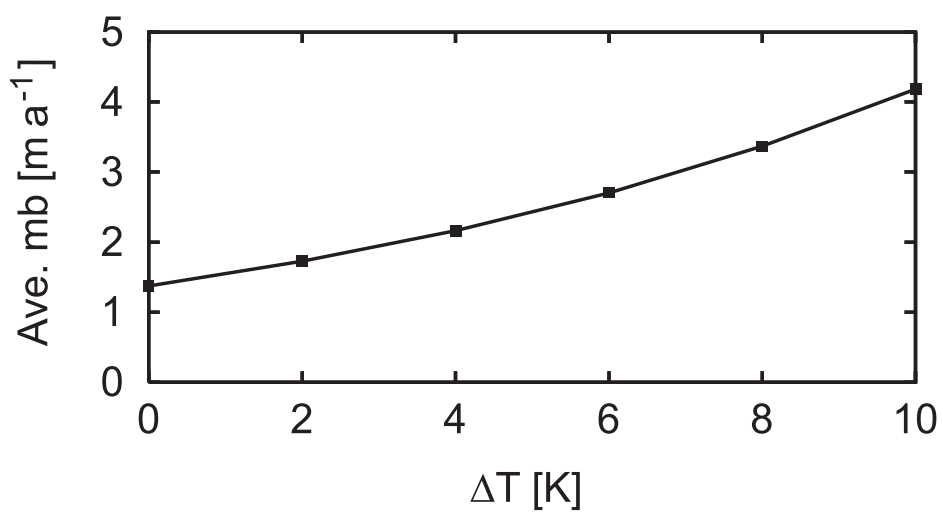

Figure 12: Average mass balance of the Ross Ice Shelf for the global-warming runs GW02-GW10 $(\Delta T=2 \ldots 10 \mathrm{~K})$ and the reference run REF $(\Delta T=0 \mathrm{~K})$.

There are further possible impacts of global warming on ice shelves which have not been dealt with in our diagnostic approach. Warming of the atmosphere leads to summer melting events in which melt water fills the ice crevasses. These filled crevasses exert a larger pressure on their walls than those filled by air, and therefore show increased propagation in the vertical direction. As a consequence, the likelihood of large break-up events is increased further (Weertman 1973, Scambos et al. 2000). Warming changes also the sea ice extent (Kwok and Comiso 2002) and via that the ocean temperature and the melting underneath the ice shelves. Therefore, ablation due to bottom melting becomes more likely and competes with the more often realized iceberg calving as the dominant mechanism for mass loss (Vaughan 1998). 


\begin{tabular}{ll}
\hline Sim. code & Description (parameter studies) \\
\hline REF & Reference simulation as defined in Sect. 4 \\
ES058 & Stress enhancement $E_{\mathrm{s}}=0.58$ \\
ES100 & Stress enhancement $E_{\mathrm{s}}=1$ \\
IT080 & Ice-thickness scale factor $f=0.8$ \\
IT120 & Ice-thickness scale factor $f=1.2$ \\
VS000 & Zero inflow at the grounding line \\
VS200 & Double inflow at the grounding line \\
GL10 & Grounding line of the ice rises moved $10 \mathrm{~km}$ outward \\
GL20 & Grounding line of the ice rises moved $20 \mathrm{~km}$ outward \\
PST & Surface-temperature parametrization by King and Turner (1997) \\
LTP & Linear ice-temperature profile \\
\hline Sim. code & Description (global-warming simulations) \\
\hline GW02 & Surface-temperature increase $\Delta T=2 \mathrm{~K}$ \\
GW04 & Surface-temperature increase $\Delta T=4 \mathrm{~K}$ \\
GW06 & Surface-temperature increase $\Delta T=6 \mathrm{~K}$ \\
GW08 & Surface-temperature increase $\Delta T=8 \mathrm{~K}$ \\
GW10 & Surface-temperature increase $\Delta T=10 \mathrm{~K}$ \\
\hline
\end{tabular}

Table 3: Set-ups for the simulations of the Ross Ice Shelf. 


\section{Conclusion}

In our diagnostic model, the dynamics of the Ross Ice Shelf has been found to be very sensitive to the flow enhancement factor, the ice thickness and the ice temperature, but robust against inflow velocities from ice streams, glaciers and ice rises except for narrow boundary zones around the grounding lines. It has further been demonstrated that the two ice rises within the ice shelf, Roosevelt Island and Crary Ice Rise, efficiently stabilize the ice shelf by slowing down the coastward ice flow due to lateral drag. An increase of the surface temperature of several degrees, which the Ross Ice Shelf may experience during the 21st century as a consequence of global warming, will entail distinctly increased iceflow velocities and, speculatively, reduces the contact between the ice shelf and the ice rises due to intensified crevassing. Since these effects are not likely to be compensated by increased mass supply at the surface or the base, the ice shelf will experience significant thinning, which ultimately poses a serious threat to the stability of the ice shelf.

\section{Acknowledgements}

The constructive comments by the editor, R. Anderson, as well as the associate editor and two referees (anonymous) are gratefully acknowledged. We also thank F. Ng for helpful remarks on an early version of the manuscript. This work was supported by the German Research Foundation (Deutsche Forschungsgemeinschaft, DFG) under grant no. HU 412/26-1/2.

\section{References}

Bamber, J. L., and D. G. Vaughan (2000), Widespread Complex Flow in the Interior of the Antarctic Ice Sheet, Science, 287, 1248-1250.

Baral, D. R., K. Hutter, and R. Greve (2001), Asymptotic theories of large-scale motion, temperature, and moisture distribution in land-based polythermal ice sheets: A critical review and new developments, Appl. Mech. Rev., 54(3), 215-256.

Bindschadler, R., P. Vornberger, D. Blankenship, T. Scambos, and R. Jacobel (1996), Surface velocity and mass balance of the Ice Streams D and E, West Antarctica, Journal of Glaciology, 42(142), 461-475.

Bindschadler, R. A., and T. A. Scambos (1991), Satelite-Image-Derived Velocity Field of an Antarctic Ice Stream, Science, 252, 242-246. 
Bindschadler, R. A., X. Chen, and P. L. Vornberger (1997), Surface velocity and strain rated at the onset of ice stream D, West Antarctica, Antarctic Journal of the United States, 32(5), 41-43.

Clough, J. W., and B. L. Hansen (1979), The Ross Ice Shelf Project, Science, 203, 433-434.

Crary, A. P. (1963), Results of United States Traverses in East Antarctica, 1958-1961, IGY Glaciological Report, American Geographical Society, $\%$.

Crary, A. P., E. S. Robinson, H. F. Bennett, and W. W. J. Boyd (1962), Glaciological Regime of the Ross Ice Shelf, Journal of Geophysical Research, 67(7), 2791-2807.

Cubasch, U., G. A. Meehl, G. J. Boer, R. J. Stouffer, M. Dix, A. Noda, C. A. Senior, S. Raper, and K. S. Yap (2001), Projections of future climate change, in Climate Change 2001: The Scientific Basis. Contribution of Working Group I to the Third Assessment Report of the Intergovernmental Panel on Climate Change, edited by J. T. Houghton, Y. Ding, D. J. Griggs, M. Noguer, P. J. van der Linden, X. Dai, K. Maskell, and C. A. Johnson, pp. 525-582, Cambridge University Press, Cambridge etc.

Determann, J. (1991), Das Fließen von Schelfeisen - numerische Simulation mit der Methode der finiten Differenzen, Reports of Polar Research, vol. 83, Alfred Wegner Institut für Polar- und Meeresforschung, Bremerhaven, Germany.

Fortuin, J. P. F., and J. Oerlemans (1990), Parameterisation of the annual surface temperature and mass balance of Antarctica, Annals of Glaciology, 14, 78-84.

Fujino, K., E. L. Lewis, and R. G. Perkin (1974), The Freezing Point of Seawater at Pressures up to 100 Bars, Journal of Geophysical research, 79(12), 1792-97.

Gow, A. J. (1963), The inner structure of the Ross Ice Shelf at Little America V, Antarctica, as revealed by deep core drilling, International Association of Scientific Hydrology/Comm. of Snow and Ice Pub., 61, 272-284.

Herzfeld, U. C., R. Stosius, and M. Schneider (2000), Geostatistical methods for mapping antarctic ice surfaces at continental and regional scale, Annals of Glaciology, 30, 76-82.

Hooke, R. L. (1981), Flow Law for Polycrystalline Ice in Glaciers: Comparison of Therretical Predictions, Laboratory Data, and Field Measurements, Reviews of Geophysics and Space Physics, 19(4), 664-672. 
Houghton, J. T., Y. Ding, D. J. Griggs, M. Noguer, P. J. van der Linden, X. Dai, K. Maskell, and C. A. Johnson (Eds.) (2001), Climate Change 2001: The Scientific Basis. Contribution of Working Group I to the Third Assessment Report of the Intergovernmental Panel on Climate Change, Cambridge University Press, Cambridge etc.

Humbert, A. (2004), Simulations of the flow of the Ross Ice Shelf, Antarctica: Parameter sensitivity tests and temperature-dependent rate factor, Doctoral thesis, Department of Mechanics, Darmstadt University of Technology, Germany.

Humbert, A., and T. A. Scambos (2005), A mean annual ice surface temperature distribution for the Ross Ice Shelf, Antarctica, J. Glaciol., to be submitted.

Hutter, K. (1983), Theoretical Glaciology; Material Science of Ice and the Mechanics of Glaciers and Ice Sheets, D. Reidel Publishing Company, Dordrecht, The Netherlands.

Huybrechts, P. (1990), A 3D-model for the Antarctic ice sheet: a sensitivity study on the glacial-interglacial contrast, Climate Dynamics, 5, 79-92.

Huybrechts, P. (1992), The Antarctic ice sheet and environmental change: a threedimensional modelling study, Reports on Polar Research No. 99, Alfred Wegener Institute for Polar and Marine Research, Bremerhaven.

King, J. C., and J. Turner (1997), Antarctic Meteorology and Climatology, Cambridge University Press.

Kwok, R., and J. C. Comiso (2002), Spatial patterns of variability in Antarctic surface temperature: Connections to the Southern Hemisphere Annular Mode and the Southern Oscillation, Geophys. Res. Lett., 29(14), 1705, doi:10.1029/2002GL015415.

Lythe, M. B., D. G. Vaughan, and the BEDMAP Consortium (2000), BEDMAP bed topography of the Antarctic. 1:10,000,000 scale map, BAS (Misc) 9. Cambridge, British Antarctic Survey.

MacAyeal, D. R., and R. H. Thomas (1986), The effects of basal melting on the present flow of the Ross Ice Shelf, Antactica, Journal of Glaciology, 32, 72-86.

MacAyeal, D. R., V. Rommelaere, P. Huybrechts, C. L. Hulbe, J. Determann, and C. Ritz (1996), An ice-shelf model test based on the Ross Ice Shelf, Antarctica, Annals of Glaciology, 23, 46-51. 
Neal, C. S. (1979), The dynamics of the Ross ice shelf revealed by radio echo-sounding, Journal of Glaciology, 24(90), 295-307.

Paterson, W. S. B. (1994), The Physics of Glaciers, 3rd ed., Pergamon Press, Oxford etc.

Rommelaere, V., and D. R. MacAyeal (1997), Large-scale rheology of the Ross Ice Shelf, Antarctica, computed by a control method, Ann. Glaciol., 24, 43-48.

Rommelaere, V., and C. Ritz (1996), A thermomechanical model for ice-shelf flow, $A n$ nals of Glaciology, 23, 13-20.

Sanderson, T. J. O. (1979), Equilibrium profile of ice shelves, Journal of Glaciology, $24(90), 435-459$.

Savvin, A. A., R. Greve, R. Calov, B. Mügge, and K. Hutter (2000), Simulation of the Antarctic ice sheet with a three-dimensional polythermal ice-sheet model, in support of the EPICA project. II. Nested high-resolution treatment of Dronning Maud Land, Antarctica, Ann. Glaciol., 30, 69-75.

Scambos, T. A., R. A. Bindschadler, M. J. Dutkiewicz, and J. C. Wilson (1992), Application of image cross-correlation to the measurement of glacier velocity using satellite image data, Remote Sensing Environ., 42(3), 177-186.

Scambos, T. A., C. Hulbe, M. Fahnestock, and J. Bohlander (2000), The link between climate warming and break-up of ice shelves in the Antarctic Peninsula, Journal of Glaciology, 46(154), 516-530.

Shabtaie, S., and C. Bentley (1979), Investigation of bottom mass-balance rates by electrical resistivity soundings on the Ross ice shelf, Antarctica, Journal of Glaciology, $24(90), 331-343$.

Shumskiy, P. A., and M. S. Krass (1976), Mathematical models of ice shelves, Journal of Glaciology, 17(77), 419-432.

Thomas, R. H. (1978), The equilibrium state of the eastern half of the ross ice shelf, Journal of Glaciology, 20(84), 509-518.

Thomas, R. H., D. R. MacAyeal, D. H. Eilers, and D. R. Gaylord (1984), Glaciological studies on the Ross Ice Shelf, Antarctica, 1973-1978, Antarctic Research Series, 42(Paper 2), 21-53. 
van der Veen, C. J. (1999), Fundamentals of Glacier Dynamics, A. A. Balkema, Rotterdam.

Vaughan, D. G. (1998), A new classification scheme for ice shelves based on mechanisms of mass gain and loss, Polar Record, 34(188), 56-58.

Weertman, J. (1973), Can a water-filled crevasse reach the bottom surface of a glacier?, International Association of Scientific Hydrology Pub., 95, 139-145.

Weis, M. (2001), Theory and finite element analysis of shallow ice shelves, Electronic Publications Darmstadt No. 171, http://elib.tu-darmstadt.de/diss/000171/, Doctoral thesis, Department of Mechanics, Darmstadt University of Technology, Germany.

Weis, M., R. Greve, and K. Hutter (1999), Theory of shallow ice shelves, Cont. Mech. Thermodyn., 11(1), 15-50.

Zotikov, I. A. (1986), The Thermophysics of Glaciers, D. Reidel Publishing Company, Dordrecht, The Netherlands. 